\title{
Reconfiguración y monumentalización de la puerta sur del oppidum oretano de El Cerro de las Cabezas (Valdepeñas, Ciudad Real) (ss. V-III a.C.) ${ }^{1}$
}

\section{Reconfiguration and monumentalization of the southern gate of the Iberian oppidum of Cerro de las Cabezas (Valdepeñas, Ciudad Real) (5th-3rd century BC)}

\author{
Jorge del Reguero González ${ }^{2}$
}

Recibido: 26-02-2019

Aceptado: 25-09-2019

\begin{abstract}
Resumen
A lo largo de la Historia, las elites políticas siempre han instrumentado su poder, entre otras consideraciones, mediante la monumentalización de su arquitectura. En este sentido, las murallas de los asentamientos han cumplido perfectamente este papel, pues no se han limitado únicamente a su función defensiva, sino también a su valor simbólico. Como consecuencia de ello, las puertas de acceso -punto de inflexión entre lo urbano y lo rural- han servido como una escenografía inmejorable para expresar el poder. En estas páginas pretendemos ejemplificar dicho fenómeno en el caso de la puerta sur del oppidum oretano de El Cerro de las Cabezas (Valdepeñas, Ciudad Real). Una compleja construcción, dilatada en el tiempo, donde hemos definido sucesivas fases constructivas que denotan los importantes cambios que sufrió este espacio entre los siglos V y III a.C. Todo ello no es sino el reflejo de una progresiva influencia púnica que, llegado un punto, nos permite proponer una presencia física de los mismos en la Oretania septentrional.
\end{abstract}

Palabras clave:

arquitectura militar, técnicas constructivas, mundo púnico, cultura ibérica, Oretania, El Cerro de las Cabezas.

Abstract

Throughout history, political elites have always implemented their power, among other considerations, through the monumentalization of their architecture. In this sense, the walls of the settlements have perfectly fulfilled this role, since they have not been limited solely to their defensive function, but also to their symbolic value, associated with

1 Este trabajo se inscribe dentro del Proyecto de Investigación del patrimonio arqueológico y paleontológico de Castilla-La Mancha: "Investigación historiográfica y arqueología no invasiva para el conocimiento urbano y territorial del oppidum del Cerro de las Cabezas. Fase II" (SBPLY/18/180801/000070). Agradecemos al Dr. Juan Blánquez Pérez y a la Dra. Lourdes Roldán Gómez toda la ayuda prestada para la materialización del trabajo de investigación que presentamos en estas páginas. Asimismo, queremos dar las gracias a Julián Vélez Rivas y José Javier Pérez Avilés por toda la documentación facilitada sobre los trabajos arqueológicos desarrollados en la muralla sur de El Cerro de las Cabezas.

2 Departamento de Prehistoria y Arqueología. Universidad Autónoma de Madrid.jorge.delreguero@uam.es; orcid.org/0000-00026033-7487. 
power. Consequently, the access doors - a point of inflection between the urban and the rural spaces- have served as an unbeatable scenery to express power. In these pages, we intend to exemplify this phenomenon with the case of the southern gate of the Iberian oppidum of Cerro de las Cabezas, in Valdepeñas (Ciudad Real). A complex construction, in which we have been able to define successive construction phases, which exemplifies the important changes that this space suffered between the 5th and 3rd centuries BC. All this is but the reflection of a progressive Punic influence that, at some point, allows us to propose a physical presence of them in the northern Oretania.

\section{Key words:}

military architecture, construction techniques, Punic world, Iberian culture, Oretania, El Cerro de las Cabezas.

\section{INTRODUCCIÓN}

Las puertas de acceso a las urbes, como límite del mundo urbano y rural, se han considerado tradicionalmente como uno de los espacios más significativos del entramado urbano, fiel reflejo del crecimiento y evolución de una ciudad. Este hecho nos obliga a pensar en las puertas no sólo como lugares de paso y control, sino como un indicador de los cambios políticos, sociales, económicos y culturales de las sociedades urbanas. Con este planteamiento inicial, las puertas de acceso a los oppida deben ser consideradas como parte de un sistema defensivo con una clara lectura ideológica que, como bien señala Brun (2001: 39), debemos relacionar con la manifestación del poder de la comunidad: "la taille et l'indéniable qualité esthétique de ces remparts, surtout de leurs portes monumentales, constituaient une manifestation de prestige et de pouvoir".
La importante carga ideológica que desprenden las puertas de acceso de los oppida y su consecuente monumentalidad, como parte del entramado defensivo de la ciudad, serán las bases principales del trabajo que presentamos en estas páginas. En este sentido, merece la pena recordar cómo la cultura ibérica se configuró con un nuevo lenguaje de poder, tal y como ocurrió con la escultura al servicio de las elites o la monumentalidad de las puertas de acceso, herramientas todas ellas propias de las sociedades protourbanas. Así, queremos incidir en cómo las murallas, en general, y las puertas de acceso, en particular, no tuvieron una única aplicación de carácter defensivo, sino que también predominaron otros factores simbólicos e ideológicos. Ello encaja con la tesis de Almagro-Gorbea (1994: 28) para explicar cómo los ambientes fortificados de la Edad del Hierro "no tuvieron una función exclusivamente defensiva, sino que, ideológicamente, fueron un

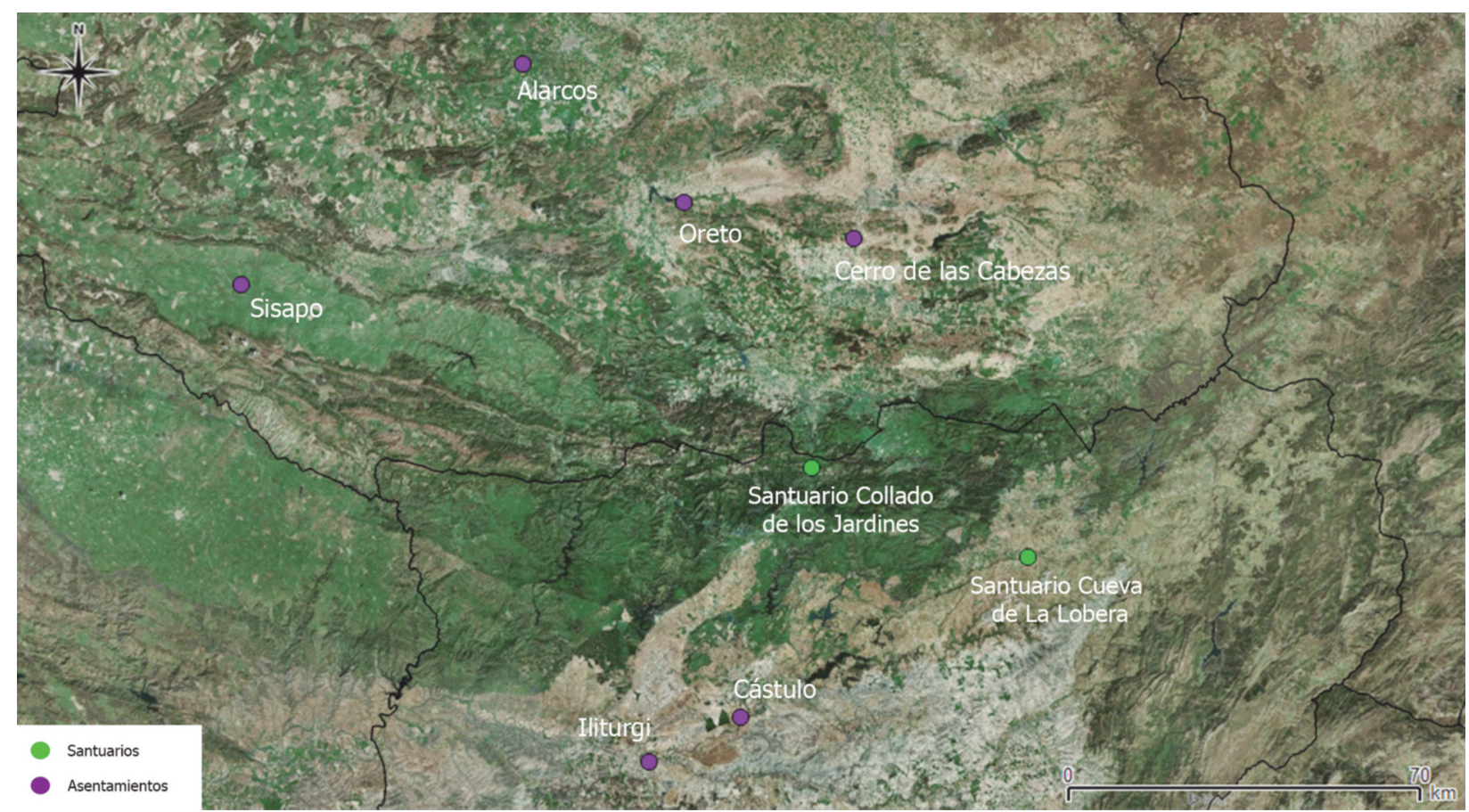

Figura 1. Mapa de distribución de yacimientos de la Oretania. Elaboración propia. 
símbolo que delimitaba el espacio sacro-político del territorio definido como «urbano» comprendido dentro de su recinto, con su correspondiente protección religiosa, estatus y prestigio político".

Así, pues, nuestro trabajo se contextualiza dentro de los oppida ibéricos situados en la Oretania septentrional (García Huerta et alii., 2015), caso de Alarcos o Sisapo (Fig. 1). Para entender el proceso de monumentalización en este contexto deberemos tener en cuenta tres aspectos: "intercambio estable a larga distancia de bienes de prestigio, sociedades guerreras y generalización del hábitat fortificado", premisa planteada por Berrocal-Rangel (2004: 34) para referirse a la generalización del poblamiento fortificado, en el Alto Guadalquivir, a partir del s. VI a.C. Aunque este fenómeno se documenta en la Meseta Sur un siglo después, el mensaje que trae consigo la fortificación va mucho más allá del papel meramente defensivo, pues el oppidum se concibe como un símbolo del poder que acoge a la comunidad.

Como decimos, partiendo de estos postulados teóricos, las puertas de acceso al oppidum de El Cerro de las Cabezas (Valdepeñas, Ciudad Real), son un ejemplo excepcional. En efecto, a partir del siglo V a.C. los accesos sufrirán sucesivas remodelaciones que no es sino el reflejo de una urbe en continuo crecimiento ${ }^{3}$, fruto de una posición geográfica privilegiada. La reconfiguración y la monumentalización de los accesos principales son un factor más de la complejidad acaecida del proceso de fortificación de la urbe, al igual que ocurre con otros elementos defensivos como los antemurales o los fosos, esto último bien constatado en la muralla sur de El Cerro de las Cabezas.

En nuestro caso particular, nos vamos a centrar en las remodelaciones que sufrió la puerta sur de El Cerro de las Cabezas, la cual configuró un acceso flanqueado por dos torres, modelo conocido en gran parte del mundo ibérico (Moret, 1996: 121). Evidentemente, este hecho lo debemos entender, primero, desde un punto de vista defensivo, pues no debemos olvidar que las puertas son uno de los puntos más débiles en cualquier lienzo murario, de ahí que se concentre buena parte de los esfuerzos tecnológicos en su fortificación (Montanero y Asensio, 2009: 178). En segundo lugar, como ya venimos anunciando, la sucesiva monumentalidad de la puerta sur de El Cerro de las Cabezas llevará consigo un importante factor ideológico como máxima expresión del poder del oppidum. Todo ello, a su vez, se debe poner en relación con el contexto espacial de la puerta sur, pues también hablamos de un ambiente de carácter económico con la presencia de grandes almacenes agrícolas -el espacio interno de los propios bastiones que flanquean la puerta sur-. En definitiva, todos estos elementos nos facilitarán entender la naturaleza social del urbanismo en época ibérica y la complejidad que lleva consigo (Bendala et alii., 1987), todo ello en un creciente interés de las elites emergentes por el control territorial.

\section{LA MONUMENTALIZACIÓN DE LAS PUERTAS DE ACCESO: UNA LECTURA IDEOLÓGICA}

Podemos decir que, a lo largo del tiempo, el Poder siempre ha intentado expresar toda su fuerza en los accesos a las urbes mediante la monumentalización de los conjuntos arquitectónicos que conforman estos espacios. Evidentemente, esto se ha producido desde un punto de vista propagandístico para exteriorizar el poder de las elites políticas en un espacio de enorme concurrencia (Montanero y Asensio, 2009). En este sentido, durante la segunda mitad del I milenio a.C., tanto los enclaves costeros como los oppida localizados en el interior de la Península Ibérica sufrieron sucesivas reformas en las puertas que obedecen a programas de monumentalización del espacio arquitectónico.

Así, por ejemplo, en la ciudad púnica de Carteia (San Roque, Cádiz) se ha podido documentar un proyecto de remodelación y monumentalización de la puerta sur a finales del siglo III a.C. (Roldán et alii., 2003: 192-195; Roldán et alii., 2006: 533-536). Este programa de remodelación arquitectónica e innovación tecnológica se ha puesto en relación con la política de los Barca en la Península Ibérica, como evidencia un ambicioso plan defensivo-económico con la construcción de una potente muralla de casamatas (Blánquez y Roldán, 2009; Blánquez et alii., 2017: 533). En la fosa de fundación de una de las casamatas apareció una moneda de la ceca Ibusim (Ibiza), emitida con anterioridad al 214 a.C., junto con cerámicas de barniz negro, lo que permitió fechar este conjunto arquitectónico. La puerta monumentalizada (Fig.

\footnotetext{
3 Hablamos de crecimiento en sentido de riqueza mediante la construcción de grandes almacenes agrícolas. El perímetro urbano, sin embargo, no crece más allá del circuito murario e, incluso, el trazado urbano con el eje viario principal preexiste desde los primeros momentos del asentamiento.
} 
2a), con acceso en codo y subida en rampa, estaba materializada por pseudosillares almohadillados que obedecen al mismo tipo de sillares que se reutilizaron en el podium de un ulterior templo republicano, dentro de la reconfiguración urbana que sufrió la ciudad a finales del siglo II a.C. (Bendala y Roldán, 2005). Ello demuestra el importante programa constructivo que se desarrolló, en la urbe púnica de Carteia, durante el control político de la familia Bárquida.

Un conjunto arquitectónico interesante para nosotros es la Puerta de Sevilla en Carmona (Jiménez, 1989). Si bien esta puerta de acceso a la ciudad no se configuró hasta su fase altoimperial y medieval, en época púnica existe un castellum (o soporte de una estructura templaria) que dotó a la construcción de una monumentalidad reseñable mediante una fábrica de sillares almohadillados, dispuestos a soga y tizón, que muestra la implantación de una tradición arquitectónica de raigambre helenística (Blánquez, 2013: 226-231). Aunque existe un debate abierto sobre la cronología de este edificio entre aquellos que defienden que se trata de una construcción púnica de época bárquida (Jiménez, 1989; Blánquez, 2013) o romano republicano (Schattner, 2005), la Puerta de Sevilla (Fig. 2b) es un buen ejemplo para entender sobremanera la monumentalización de una urbe al tratarse de un espacio en constante cambio y reconfiguración desde sus primeros niveles de ocupación a comienzos del I milenio a.C. (Bendala y Belén, 2007).
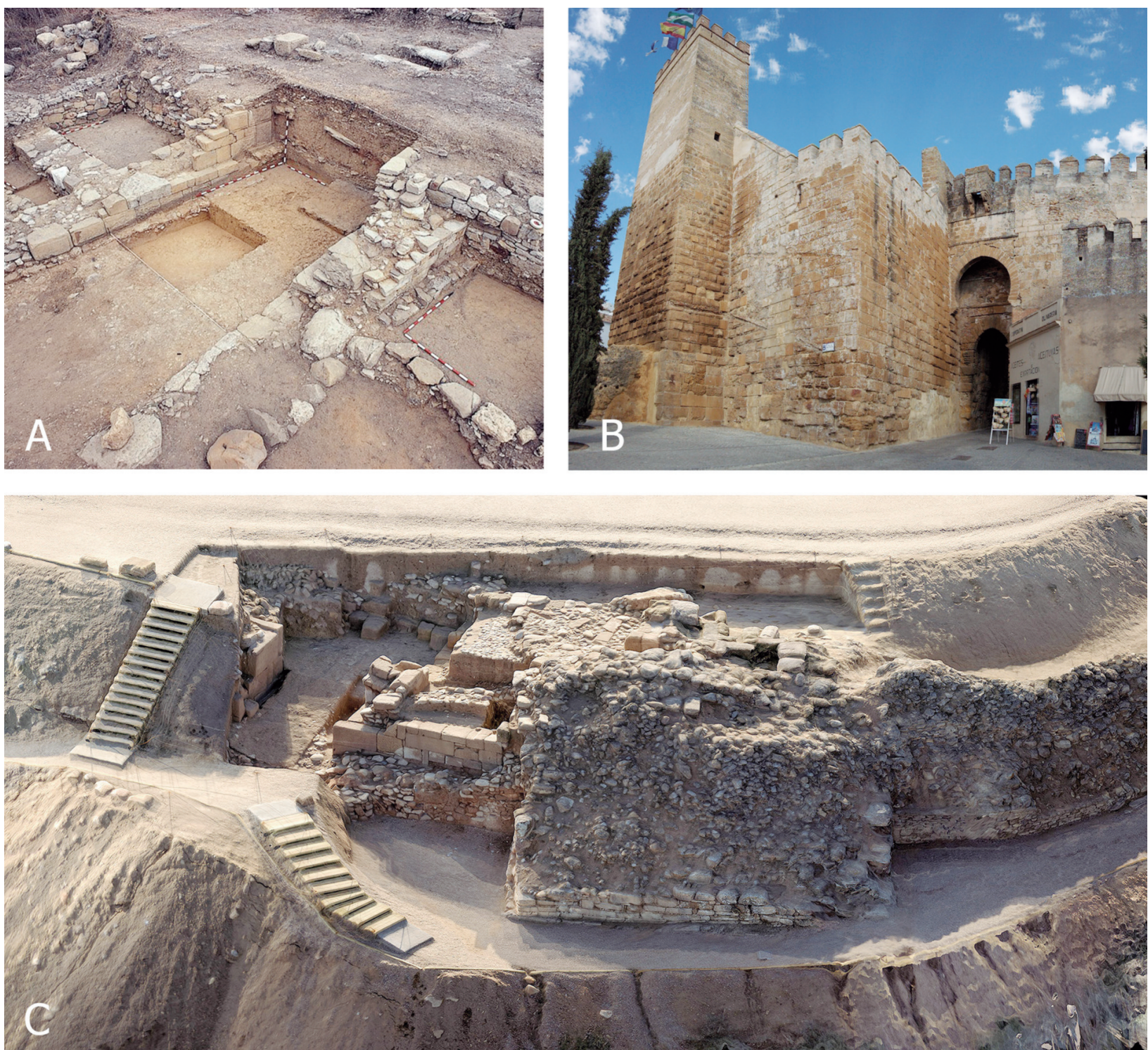

Figura 2. A) Vista general del acceso a la ciudad púnica de Carteia. Foto: J. Blánquez (1995); B) Puerta de Sevilla en Carmona. Foto: J. del Reguero (2017); C) Vista general de la Puerta Norte de Cástulo (Barba et alii., 2015: fig. 12). 
En el mundo ibérico, a partir de los siglos IV y III a.C. los accesos a los oppida también se monumentalizan. Si bien las puertas con una torre tuvieron una larga tradición desde el s. V a.C., caso de La Quéjola (San Pedro, Albacete) (Blánquez, 1993) o el Puntal dels Llops (Olocau, Valencia) (Bonet y Mata, 2002), a partir del s. IV a.C. aparecen los accesos flanqueados por dos torres, lo cual constituye una materialidad heráldica. Este tipo de accesos lo encontramos en yacimientos tan paradigmáticos como el oppidum del Castellar de Meca (Ayora, Valencia) (Alfaro y Broncano, 1992; Lorrio, 2011). En este caso, aunque el estado de conservación resulta bastante malo, se conservan las entalladuras hechas en la propia roca donde se asentarían los sillares. No disponemos de cronologías precisas para fechar este conjunto arquitectónico, aunque la documentación del tapiado de la puerta mediante sillares se ha relacionado con el momento final del poblado, frente a la presencia romana en la zona, hacia finales del siglo III o principios del II a.C. (Alfaro y Broncano, 1992: 79). Por lo tanto, la existencia de un acceso con dos potentes torres y un primer cuerpo de sillería nos aconseja pensar en una puerta de claro carácter monumental, en época ibérica, para un asentamiento que, dada su posición privilegiada, se caracterizó por un comercio fluido con el mediterráneo desde principios del I milenio a.C. (Broncano y Alfaro, 1997: 9).

Por otro lado, a partir del siglo III a.C. también se desarrolla otro tipo de acceso a los poblados iberos que ejemplifica otra forma de monumentalidad: las puertas torre. Se trata de un modelo, de influencia helenística, bien conocido en el Mediterráneo (Sconfienza, 2005: 18). En la Península Ibérica cabe destacar la Bastida de les Alcusses (Moixent, Valencia), donde la monumentalización de las puertas queda patente a través de sus entradas torreadas (Bonet y Vives-Ferrándiz, 2009: 298-299). En este poblado, además, las torres presentes en el lienzo defensivo son un elemento muy significativo dentro de su arquitectura defensiva, pues la localización de todas ellas no es trivial: dos torres en el frente meridional, entre las puertas Oeste y Sur, y otra en el límite oriental, junto a la puerta Este. Como bien señalan Bonet y Vives-Ferrándiz (2009: 292), “las torres son significativas de las zonas que merecían ser especialmente vigiladas y, por qué no, cuidadas y monumentalizadas".

Este proceso de monumentalización de los accesos a las grandes urbes también se constata en época romana republicana, siendo Cástulo un magnífico ejemplo. En efecto, en las excavaciones acometidas -en 2014- en la puerta norte (Fig. 2c), quedó expuesto un tramo de muralla con distintas fases superpuestas (Barba et alii., 2015) y un acceso rematado por dos paramentos monumentales y flanqueados, previsiblemente, por dos esculturas en forma de "león con cabeza humana", apareciendo tan sólo una de ellas in situ.

Como comentábamos, los trabajos desarrollados en la puerta norte de Cástulo permitieron fechar las diferentes fases constructivas de la muralla. Así, se ha localizado la muralla ibérica asociada a una gran torre y algunas estructuras que fueron destruidas en el s. III a.C., en el contexto de la Segunda Guerra Púnica (Barba et al., 2015: 310). Esta primera fortificación ibérica, cimentada directamente sobre el sustrato geológico, presenta un primer alzado de mampostería irregular, con un relleno a base de piedra menuda y tierra. El resto del alzado estuvo hecho con adobes, según atestiguaron los excavadores, pues se pudo documentar la caída de un potente estrato de adobes en el exterior de la muralla ${ }^{4}$. Este último elemento, la arquitectura defensiva en tierra, tuvo que ser una constante en la arquitectura ibérica con influencia orientalizante, como se ha constatado recientemente en una estratigrafía extramuros de El Cerro de las Cabezas.

A una segunda fase correspondería un nuevo lienzo defensivo, con grandes sillares almohadillados, que configuró la muralla y la puerta norte de época romana republicana. Este conjunto arquitectónico, fechado entre los siglos II y I a.C., originó que el acceso a la ciudad -por su vertiente norteestuviese dotado de una monumentalidad reseñable. Lo interesante de todo ello es cómo se ha propuesto que estos sillares, dispuestos a soga, habrían sido reutilizados de un antiguo templo de adscripción púnica (Barba et al., 2015: 315). Esta muralla refleja, pues, una ambiciosa obra al estar ubicada en la zona más elevada de la ciudad, entre dos torreones que existían previamente, provo-

\footnotetext{
${ }^{4}$ Las excavaciones realizadas en el interior de Cástulo documentaron una posible muralla de casamatas, amortizada en época republicana, lo que cuadraría muy bien con la generalización de este sistema defensivo en la Península Ibérica, en el siglo III a.C., siguiendo un modelo púnico-helenístico.
} 


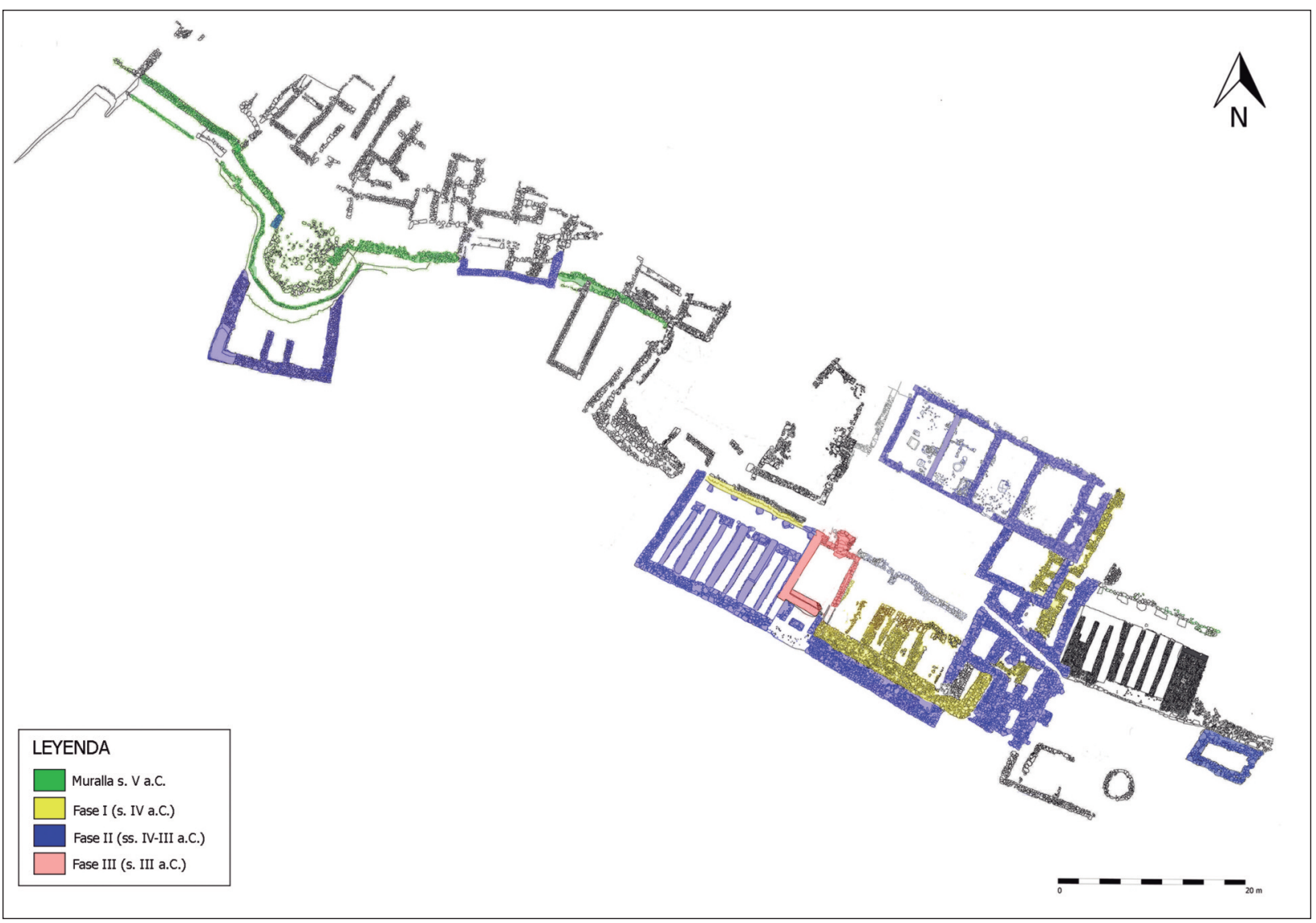

Figura 3. Fases constructivas identificadas en la muralla sur. (C) GICC, con modificaciones del autor (2018).

cando que todo el conjunto fuera visible desde largas distancias. Por lo tanto, esta puerta de los leones facilita una lectura ideológica asociada al poder, no sólo por su monumentalidad arquitectónica sino también por la presencia de una escultura de león, cuyas garras sujetan la cabeza y los antebrazos de una figura humana, lo cual se ha interpretado como el poder de Roma frente a Cartago (Barba et al., 2015: 321).

Otro ejemplo significativo de puerta monumentalizada durante época romana republicana es el oppidum de El Molón (Camporrobles, Valencia) (Lorrio, 2007). Este asentamiento, a caballo entre los ámbitos ibérico y celtibérico, tuvo una ocupación continua entre los siglos VII y I a.C. El yacimiento ocupa una superficie amesetada rodeada de fuertes escarpes que, a lo largo de su historia, han servido como defensa natural del poblado. A ello habría que sumarle su complejo sistema defensivo, destacando el acceso principal al asentamiento flanqueado por dos torres de planta cuadrangular. Lo interesante de este oppidum, en relación con el caso que nos ocupa, es que mientras que buena parte de las construcciones se han fechado en el siglo IV a.C., la puerta principal sufrió sucesivas remodelaciones en las etapas más avanzadas del asentamiento (Lorrio, 2007: 214), hecho que tiene -para nosotros- un importante valor simbólico. La torre sur de la puerta principal amortizó el lienzo de la antigua muralla del poblado, lo cual evidencia primero- una reconfiguración importante del acceso principal y, segundo, una monumentalización que no se limita a un sentido propagandístico del poder, sino que también lleva consigo una interpretación poliorcética pues "se podía batir [desde la torre sur] el costado desprotegido del asaltante que llevaría el escudo en el brazo izquierdo" (Lorrio, 2007: 216).

Finalmente, queremos destacar la puerta oriental de Torreparedones (Baena, Córdoba) (Morena, 2010), un acceso de carácter monumental fechado en época romana republicana entre los siglos II y I a.C.- según atestigua el hallazgo de cerámicas campaniense A y B. Hablamos de un acceso flanqueado por dos torres levantadas con grandes bloques ciclópeos que simulan sillares almohadillados, aunque las caras internas de los mismos no están labradas. En el interior de las torres aparecieron cuatro muros que forman una cruz, configurando cuatro espacios que 
se rellenarían de tierra y piedra. Además, el acceso a la ciudad poseía una doble puerta, interpretación aportada por la documentación de cuatro quicialeras talladas en grandes piezas de calcarenita. Todo ello ha dado pie a pensar en un acceso monumental con un importante componente defensivo, según denotan las torres macizas que, muy probablemente, estarían dotadas de un segundo cuerpo en mampostería o adobe (Morena et alii., 2007: 2), así como el citado sistema de doble puerta.

En definitiva, todos los casos citados anteriormente responden a "la actuación del poder en un punto trascendental de lectura ideológica como, durante siglos, han sido las puertas de acceso a las urbes" (Blánquez, 2013: 226). Este supuesto lo hemos constatado tanto en asentamientos protohistóricos como en las fases romanas de época republicana, es decir, durante buena parte del I milenio a.C. A continuación, nos centraremos en la puerta sur del oppidum de El Cerro de las Cabezas como modelo del fenómeno citado.

\section{LA PUERTA SUR DEL OPPIDUM IBÉRICO de El Cerro de las Cabezas}

A través de un estudio pormenorizado de las técnicas y los materiales constructivos del conjunto arquitectónico que conforma la puerta sur (en adelante, puerta S) de El Cerro de las Cabezas, junto con una reinterpretación de todo este espacio en relación con el entramado urbano, hemos podido definir diferentes pero sucesivas fases y momentos constructivos en dicha puerta de acceso al oppidum (Fig. 3). Tradicionalmente, el lienzo original de la muralla se ha fechado en el siglo $\mathrm{V}$ a.C. (Vélez et al., 2004; Torres et al., e.p.), sistema caracterizado por la planimetría curvilínea que presentan los torreones de la muralla, previa implantación de obras cuadrangulares como torres o bastiones. Dicho trazado murario se pierde en nuestra área de estudio y aparece de nuevo en la parte baja del poblado, junto a la actual Autovía A4. Sin embargo, el adelantamiento urbanístico que se produce con la puerta $\mathrm{S}$ del oppidum debe responder a diferentes remodelaciones acontecidas a partir de finales del siglo $\mathrm{V}$ a.C.

\section{FASE I}

Si definimos las distintas fases y momentos constructivos bajo una lectura propia de la arqueología de la arquitectura, podemos comenzar señalando que, a finales del siglo $\mathrm{V}$ o principios del IV a.C., se produce una reconfiguración de la puerta $S$ a través de un adelantamiento del conjunto arquitectónico ${ }^{5}$ (Fig. 4a). Este adelantamiento se materializó mediante la construcción del bastión E. Este edificio se asocia a construcciones anexas -en parte conservadas- que ocuparían el espacio establecido entre el lienzo de muralla del siglo $\mathrm{V}$ y el físico adelantamiento del bastión E. De esta manera, en una primera fase se acometió la construcción de dicho bastión, configurando así una puerta de acceso con una torre. Con esta primera fase relacionamos un sistema de contrafuertes que actuó como refuerzo de las construcciones organizadas en torno al bastión E, debido a la pendiente del terreno en dirección W-E. La fecha relativa que utilizamos viene apoyada por la documentación de copas tipo Cástulo en las estructuras anexas al bastión E (Vélez y Pérez, 2008b), construcciones que serían amortizadas en una segunda fase mediante la construcción del bastión W.

El hallazgo de copas tipo Cástulo en este sector nos permite manejar una cronología muy bien definida, pues esta vajilla se encuadra entre fines del siglo $\mathrm{V}$ e inicios del siglo IV a.C. Sin embargo, es más que probable que dicho repertorio cerámico mantuviese su uso durante la primera mitad del siglo IV a.C., ya que se trata de una vajilla de lujo que "se amortizaría en fechas muy posteriores a su fabricación, al ser consideradas no tan sólo un valioso bien mueble, sino un objeto de prestigio" (Gracia Alonso, 2005: 1192-1193). Esta premisa se entiende aún más en un territorio como la Oretania septentrional, muy lejos de los principales focos comerciales portuarios ${ }^{6}$. Cabe destacar cómo esta vajilla cerámica de formas áticas de barniz negro se ha documentado en otros yacimientos como Sisapo (La Bienvenida, Ciudad Real) (Zarzalejos et alii., 1995), Calatrava la Vieja (Miguel Naranjo, 2014) o Libisosa (Lezuza, Albacete) (Uroz Sáez, 2012: 92), entre otros.

\footnotetext{
5 El adelantamiento que sufrió la puerta $\mathrm{S}$ no nos debe sorprender, puesto que se han documentado otros casos similares donde las puertas de entrada a los oppida se adelantaron debido a su expansión urbanística, siendo un buen ejemplo de ello el oppidum del Castellar de Meca (Alfaro y Broncano, 1992: 73).

6 Los principales motores comerciales en Occidente, en el contexto del comercio ampuritano, fueron Ibiza (Gracia Alonso, 1994: 181) y Cádiz (Barros, 2005: 941).
} 


\section{FASE II}

Desde el punto de vista arqueoarquitectónico, defendemos que el bastión E se construyó en un momento más antiguo que el bastión W, hipótesis apoyada por el tipo de aparejo de los muros de carga y los muros divisorios de ambos edificios, por la disposición de los edificios sabiendo que el bastión E se adaptó a la topografía del terreno mientras que, para la construcción del bastión W, se aterrazó la superficie, y, muy especialmente, por las ampliaciones innecesarias- del muro sur del bastión E para alinearse con el bastión W (Reguero, 2018). Cada uno de estos argumentos tienen un peso diferente, pero todos ellos se complementan para defender nuestra hipótesis.

En el primer caso, podemos destacar cómo los muros perimetrales de ambos edificios son significativamente distintos: mientras el bastión $\mathrm{W}$ presenta unos muros con una potente fosa de cimentación, con grandes bloques de piedra cuarcita y caliza (Fig. 4b), el bastión E difiere al tener una cimentación con piedras cuarcíticas de pequeño y mediano tamaño. La presencia de piedra caliza en la cimentación se ha podido constatar en otros edificios del oppidum que se superponen a construcciones anteriores al siglo IV a.C., caso de la construcción del desagüe ubicado en el área intramuros de la muralla sur que, como bien resaltan Vélez Rivas y Pérez Avilés (2008b: fig. 4), se levanta sobre una edificación anterior. Por lo tanto, la aparición de caliza en la cimentación de los edificios podría ser indicativo de aquellas
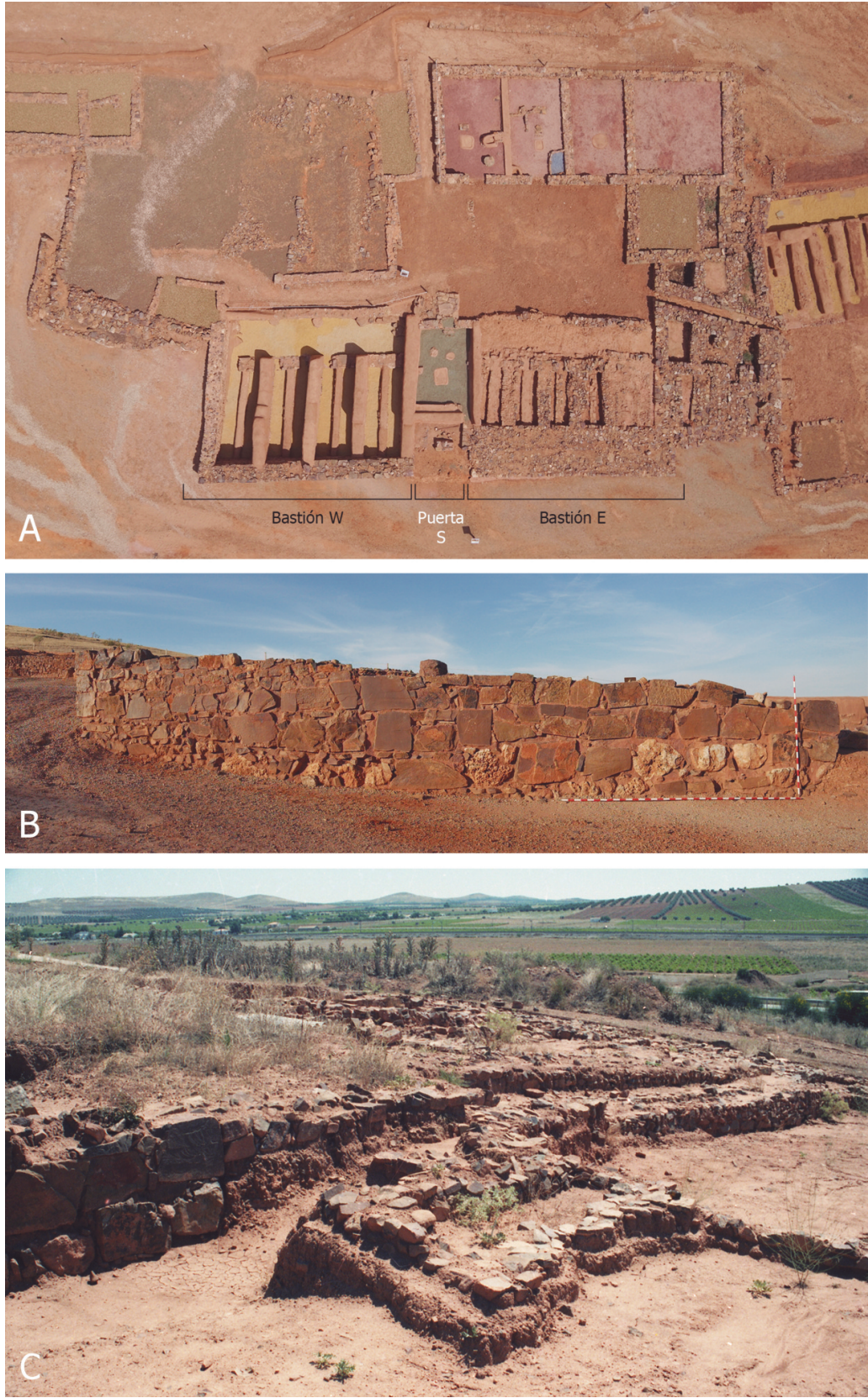

Figura 4. A) Vista general de la puerta sur de El Cerro de las Cabezas. Foto: GICC (2016); B) Muro sur del bastión W. Foto: J. del Reguero (2017); C) Cegamiento de la puerta sur y posible proteichisma.

Foto: Ayto. Valdepeñas. Archivo Fotográfico Cerro de las Cabezas, $N^{o}$ Inv. CC_00022 (ca. 1995).

estructuras de finales del siglo IV y principios del siglo III a.C., configurando el asiento de aquellos muros con una complejidad mayor. Al igual que los muros perimetrales de los bastiones presentan disimilitudes, los muros internos de ambos edificios -división de los almacenes- también difieren: en el bastión $\mathrm{W}$ documentamos zócalos de mampostería, con caras planas, a base de piedras cuarcita y caliza de mediano tamaño, mientras que los muros divisorios del bastión $\mathrm{E}$ presentan unos zócalos de mampostería irregular,

con mampuestos de pequeño tamaño sin un orden aparente.

En cuanto al segundo argumento citado, la disposición de los edificios, ya hemos dicho como el bastión E se construyó adaptándose a la topografía del terreno, visible por cota tanto en los muros internos como en los cuatro bloques de cuarcita hallados en el pasillo que compartimenta el espacio interno del almacén, los cuales trabajarían como 
bases de postes de madera que soportarían una segunda planta del edificio. Sin embargo, para el bastión W se aterrazó la superficie, hecho que no nos debe sorprender dada la naturaleza monumental que caracteriza a este último edificio.

Finalmente, consideramos esencial destacar cómo el muro sur del bastión E, siendo parte del entramado defensivo del oppidum, sufrió hasta dos ampliaciones para alinearse con la construcción del bastión W. Se trata de un rasgo indicativo sobre cómo el bastión E ya existía cuando se levantó el bastión W. De este modo, todo este proceso configuró una nueva puerta desde la vertiente meridional.

De esta manera, la construcción del bastión W genero un acceso flanqueado por bastiones, algo frecuente -como ya hemos visto- en el mundo ibérico (Moret, 1996: 121). Así, esta segunda fase constructiva se debe encuadrar en la segunda mitad del siglo IV a.C.,pues los excavadores del bastión W manejan esta fecha para este edificio con el apoyo de los materiales arqueológicos aparecidos en contexto (Vélez y Pérez, 2009).

Esta segunda fase evidencia una planificación constructiva pensada con previsión de problemas a solucionar. Ejemplo de ello fue la construcción del canal de desagüe, citado anteriormente, para evacuar las aguas a las afueras del oppidum, con el fin de evitar que las escorrentías impulsadas por las fuertes pendientes quedasen en el espacio intramuros.

Con esta fase que, como venimos diciendo, debemos encajar en la segunda mitad del siglo IV a.C., asociamos el llamado "edificio tripartito" (Vélez y Pérez, 2008a: 130), conjunto arquitectónico que se apoya sobre el sistema de contrafuertes de la primera fase. Este edificio se interpreta como un espacio productivo donde predominaría la molienda del grano almacenado en los bastiones. $\mathrm{La}$ documentación de espacios de molienda favorece la interpretación de estos edificios como ámbitos de carácter comunitario, asociados al poder, tal y como se ha defendido para otros yacimientos ibéricos como El Cerro de la Cruz (Almedinilla, Córdoba) (Quesada et alii., 2014: 111-112).

\section{FASE III}

Finalmente, defendemos una tercera fase constructiva ya en el siglo III a.C., relacionado con la construcción del santuario sur, el cual supuso la amortización del acceso meridional al oppidum (Vélez y Pérez, 2008a: 136-140; Vélez y Pérez, 2010: 29-35). Las fotografías antiguas del proceso de excavación nos han permitido identificar el cegamiento de la puerta sur mediante un muro de mampostería careada con piedra cuarcita de mediano tamaño. Asimismo, hemos podido identificar una estructura levantada frente al cegamiento de la puerta sur que, muy probablemente, responda a un proteichisma (Fig. 4.c).

Hablamos de un recurso bien conocido en la poliorcética helenística que, localizado en las puertas de acceso, actúa como elemento defensivo frente a las máquinas de asedio. Si bien este elemento resulta bastante inusual en Occidente (Tréziny, 2011: 292), la posibilidad de hablar de un proteichisma en El Cerro de las Cabezas nos permite refutar la idea de la llegada de innovaciones tecnológicas y nuevas tácticas de guerra, propias de las culturas mediterráneas, en el interior peninsular. Desde este punto de vista, podemos traer a colación otros ejemplos documentados en la Península Ibérica, bien en la I Edad del Hierro como es el primitivo antemural descubierto en el Cabezo de la Cruz (La Muela, Zaragoza) (Rodanés y Picazo, 2013-2014: 224) o, mucho más habitual, en la II Edad del Hierro con modelos orientales de raigambre helenística, siendo el caso del enclave griego de Emporion (San Martín de Ampurias, Gerona) (Sanmartí et alii., 1988; Gracia Alonso y Munilla, 2004: 653; Olmos, 2009-2011: 139), el oppidum de Puig de Sant Andreu (Ullastret, Gerona) (Oliva, 1960), el poblado ibérico del Castellet de Banyoles (Tivisa, Tarragona) (Pallarés, 1983-84), la ciudad ibero-romana del Tossal de Manises (Alicante) (Gracia Alonso, 2006: 82; Quesada, 2007: 90; Sala, 2010: 945) o el Castrejón de Capote (Higuera la Real, Badajoz) (Berrocal-Rangel, 1994: 206).

A excepción de esta última, observamos cómo todos los ejemplos se localizan en el litoral mediterráneo y responden a influencias poliorcéticas orientales durante los siglos IV y III a.C. Por lo tanto, el poder hablar de un proteichisma en El Cerro de las Cabezas, para la fase de amortización de la puerta sur en el siglo III a.C., es un rasgo muy revelador sobre la influencia púnica en la Oretania septentrional. En nuestro caso particular, bien es cierto que la tipología del posible proteichisma difiere de otros modelos citados con anterioridad al no ser una estructura longitudinal. A través de la fotografía arqueológica podemos decir que el ejemplo hallado en El Cerro de las Cabezas consiste en una estructura cuadrangular que ocupa el ancho de la puerta sur. Ello nos permite entender mejor el cegamiento del acceso meridional al oppidum puesto que, la presencia de un antemural evitaría que las máquinas de asedio tomasen contacto con un punto débil del sistema defensivo. 
En definitiva, el acceso sur al oppidum quedó amortizado en torno a la segunda mitad del siglo III a.C., en los momentos finales del poblado. Este hecho no nos debe sorprender pues dicho mecanismo -amortización de las puertas- se ha constatado en las últimas fases de otros asentamientos ibéricos. Valga como ejemplo el Castellet de Bernabé (Guérin, 2003) o el Castellar de Meca (Alfaro y Broncano, 1992: 79), este último caso vinculado con la presencia romana en la zona a finales del siglo III o inicios del II a.C. Algo parecido ocurrió con las puertas Norte y Sur de la Bastida de les Alcusses (Bonet y Vives Ferrándiz, 2009: 302-303), aunque en este caso no significó el abandono definitivo del poblado. Estos ejemplos ponen en evidencia la presencia de algún peligro externo y la necesidad de reorganizar las defensas frente a una amenaza.

\section{EL "FACTOR PÚNICO" EN EL OPPIDUM de El Cerro de las Cabezas}

Tras una sistemática recogida de datos, creemos defendible afirmar la influencia púnica que denota el conjunto arquitectónico estudiado, muy especialmente el bastión $\mathrm{W}$, puesto que refleja unas técnicas constructivas de una evidente madurez: bloques de cuarcita -con caras planasdispuestos en pseudohiladas para perseguir una horizontalidad. El hecho de que las hiladas no sean perfectas no es algo que nos deba sorprender pues la mampostería púnica tiene una marcada irregularidad, determinada por la importancia del revestimiento (Prados, 2007b: 24).

Sin embargo, esta madurez arquitectónica en la forma de construir -en comparación con el bastión E- no es el principal argumento que utilizamos para defender la influencia púnica en El Cerro de las Cabezas, sino que el argumento definitorio es la constatación de una modulación púnica en el bastión W. En efecto, el edificio presenta una planta de $21 \times 27 \operatorname{codos}^{7}$, unas dimensiones que no son baladíes pues en el marco del estudio de los módulos arquitectónicos en el mundo púnico, estos habitualmente vienen asociados en grupos de $3 \mathrm{y}$ sus múltiplos. Asimismo, en lo que respecta a la división interna del bastión como almacén sobreelevado, es reseñable cómo los muretes que elevan el nivel del suelo de uso del almacén presentan una anchura de $0,52 \mathrm{~m}$-un codo púnico- mientras que los departamentos de almacenaje presentan una anchura total de cinco codos entre el murete y los espacios intermurarios. Todos estos elementos evidencian un patrón preestablecido en la construcción del edificio que responde a una modulación púnica.

La utilización de patrones métricos procedentes del Mediterráneo nos invitan a pensar en importantes influjos de carácter púnico en los programas arquitectónicos llevados a cabo por las elites dirigentes. Esta regularidad en los esquemas constructivos viene siendo cada vez más habitual en el extremo occidental, no sólo en los ambientes costeros (Prados y Jiménez, 2017) sino también en el interior peninsular (Moret, 1998). Mención especial, por su cercanía a la Oretania, es la ciudad ibero-romana de Torreparedones, cuya torre cruciforme de la puerta noreste presenta unas medidas canónicas consistentes en múltiplos de un codo púnico. Como bien señala Moret (1998: 90), la tipología de la estructura coincide con un modelo difundido desde Siracusa en el siglo IV a.C., por lo que no sería de extrañar que este tipo de torre defensiva hubiese llegado a la Península Ibérica por influencia púnica. Se trata, al fin y al cabo, de un argumento más para defender la amplia difusión de modelos arquitectónicos mediterráneos por vía púnica.

Un factor decisivo para apoyar este argumento, la influencia púnica en la configuración de las defensas del oppidum de El Cerro de las Cabezas, es el santuario con una triada betílica localizado en el sector norte del poblado. Si bien algunos investigadores han manifestado que, tanto por el material documentado como por la tipología de los betilos, este espacio de carácter sacro no denota un influjo púnico (Seco, 2010: 425), nosotros creemos que el culto betílico que se desarrolló en este contexto refleja un claro factor púnico (Moneo et alii., 2001: 130; Manzaneda, 2017: 598-600). En efecto, la constatación de una tríada betílica nos traslada al ámbito fenicio-púnico dado que su religiosidad se singulariza por su carácter anicónico donde la divinidad se representa a través de elementos inertes como los betilos. Así, la constatación de una tríada betílica anicónica y la documentación de programas arquitectónicos de carácter púnico nos permiten defender una sustancial presencia púnica no sólo en el área levantina (Oliver, 1995; Sala,

71 codo $=0{ }^{\prime} 52 \mathrm{~m}$. 
2004; García Cardiel, 2017), sino también en la Oretania septentrional, previo a la llegada de los Barca. Debemos pensar, pues, cómo la producción cerealística provocó el interés de Cartago por este territorio, motivando la penetración de elementos culturales de carácter púnico hacia el interior peninsular.

\section{Consideraciones finales}

Las sucesivas remodelaciones que hemos podido documentar en los accesos principales de El Cerro de las Cabezas nos evidencia, en primera instancia, cómo las elites políticas expresaron su poder al actuar sobre las puertas de la ciudad, lo que nosotros interpretamos como un modo de apropiación del oppidum. Se trata de un concepto urbano propio de las culturas mediterráneas que, en nuestro caso particular, trajo consigo el mundo púnico.

Primeramente, creemos importante resaltar que, si bien hoy no podemos definir la puerta del lienzo de muralla del siglo V a.C., previo a las consiguientes remodelaciones, parece seguro que siempre hubo un acceso al oppidum por su vertiente meridional hasta la última fase de amortización. La perpetuación de los accesos $\mathrm{S}$ y $\mathrm{N}$ del oppidum, entre los siglos V y III a.C., se entiende mediante la unión de estos a través del eje viario principal de la parte baja del asentamiento, pues debemos pensar que las calles principales del entramado urbano poco cambiaron a lo largo de la vida de El Cerro de las Cabezas. Es más, debemos tener en cuenta que el urbanismo ibérico siempre se caracterizó por el aprovechamiento del terreno más allá de seguir un esquema geométrico.

Si alzamos la vista a las transformaciones y la disposición global de la puerta S, nuestro hilo conductor en estas páginas ha sido la progresiva monumentalidad con la cual estuvo dotada esta puerta de acceso. Lo interesante de este hecho es que no sólo se constata en el sector meridional del oppidum, sino también en la puerta N. En efecto, en el acceso septentrional de El Cerro de las Cabezas destaca un bastión rectangular de más de $500 \mathrm{~m}^{2}$, constituido por un patio central que compartimenta el espacio interno. Este bastión de gran envergadura rompió por completo el lienzo de muralla original del siglo V a.C., lo que nos obliga a pensar-de nuevo- en la importante reforma urbanística que se acometió en los accesos al oppidum durante el siglo IV.

Esta obra concuerda con las remodelaciones que hemos identificado en la puerta S. Ello supone un argumento más para poder defender cómo los principales accesos al oppidum de El Cerro de las
Cabezas se dotaron de una monumentalidad significativa; aspecto este que, cada vez con mayor seguridad, podemos relacionar no sólo con una influencia sino más bien con una presencia púnica en la Oretania Septentrional. Esta hipótesis se apoya, tal y como hemos reflejado con anterioridad, en la constatación de una modulación arquitectónica de raigambre púnica en el bastión $\mathrm{W}$ de la puerta $\mathrm{S}$. Con todo ello, merece la pena destacar la complejidad poliorcética que denotan las puertas de acceso al oppidum: el rasgo característico de la puerta norte es su abocinamiento, sistema que evidencia la presencia de nuevas tácticas de ataque y el empleo de un nuevo armamento (Quesada, 2002-2003); en la puerta sur, por su parte, ya hemos señalado cómo la fotografía nos ha permitido documentar un proteichisma relacionado con la fase de amortización del acceso, reflejo de la llegada de nuevas ideas y tácticas de guerra al interior peninsular.

Podemos concluir señalando que la reconfiguración y la monumentalización de la puerta $\mathrm{S}$ de $\mathrm{El}$ Cerro de las Cabezas se debe poner en relación con el entramado defensivo, económico e ideológico de la urbe. Este último factor tiene, para nosotros, una clara lectura púnica. Hoy, parece indudable cómo la presencia de los Barca en la Península Ibérica tuvo unas importantes consecuencias en el plano urbanístico y arquitectónico (Bendala y Blánquez, 200203), según se constata en algunos oppida del Alta Andalucía (Prados, 2007b; Gutiérrez Soler et alii., 2017). Sin embargo, en trabajos recientes se está constatando cómo la huella púnica en el ámbito estructural y territorial de las sociedades ibéricas debe remontarse a momentos previos que, con bastantes creces, podemos situar en el siglo IV a.C. (Ferrer y Pliego, 2010; 2013). Parece claro cómo Cartago centró sus intereses en la Península Ibérica, en época prebárcida, no sólo desde el punto de vista de la explotación y control de los metales, sobre todo plata y estaño, sino también de otros productos de carácter agrícola. Con este último caso se podría entender la presencia púnica en El Cerro de las Cabezas, asentamiento cuyo motor económico fue la producción y el almacenamiento del cereal.

\section{Bibliografía}

Alfaro Arregui, Ma . del M. y Broncano Rodríguez, S. (1992): "El sistema defensivo de la puerta de entrada a la ciudad ibérica de «El Castellar de Meca» (Ayora, Valencia)". Estudios de Arqueología Ibérica y Romana. Homenaje a Enrique Pla Ballester. Serie de Trabajos Varios del S.I.P., 89: 73-81. 
Almagro-Gorbea, M. (1994): "Urbanismo de la Hispania «celtica»: castros y oppida del centro y occidente de la Península Ibérica”. En M. Almagro-Gorbea y A. Ma . Martín (coords.), Castros y oppida en Extremadura. Complutum, No Extra-4: 13-76.

Barba, V.; Fernández, A. y Jiménez, Y. (2015): “La muralla de Cástulo y la Puerta de los Leones”. En A. Ruiz Rodríguez y M. Molinero (coords.): Faén, tierra ibera: 40 años de investigación y transferencia. Universidad de Jaén. Jaén: 305-322.

Barros, P. (2005): "Cerâmicas áticas no circuito do estreito do extremo-ocidente peninsular: Quinta da queimada, Ilhéu do rosário, Faro e Tavira”. En S. Celestino Pérez y J. Jiménez Ávila (eds.), El Periodo Orientalizante. Actas del III Simposio Internacional de Arqueología de Mérida: Protohistoria del Mediterráneo Occidental, Vol. II. Anejos de AEspA, XXXV. CSIC. Mérida: 931-946.

Bendala Galán, M. y Belén Deamos, M. (2007): El nacimiento de la ciudad: la Carmona protohistórica. Editorial Universidad de Sevilla. Sevilla.

Bendala Galán, M. y Blánquez Pérez, J. (2002-2003): "Arquitectura militar púnico-helenística en Hispania”. CuPAUAM, 28-29: 145-158, https:// doi.org/10.15366/cupauam2003.29.008.

Bendala Galán, M. y Roldán Gómez, L. (2005): “El templo romano republicano de Carteia (Hispania) y su problemática arqueológica e histórica”. En X. Lafon y G. Sauron (coords.), Théorie et pratique de l'architecture romaine. Études offertes à Pierre Gros. Publications de l'Université de Provence. Aix-en-Provence: 153-166.

Bendala Galán, M.; Fernández Ochoa, C.; Fuentes Domínguez, A. y Abad Casal, L. (1987): “Aproximación al urbanismo prerromano y a los fenómenos de transición y de potenciación tras la conquista". En VV.AA., Los asentamientos ibéricos ante la romanización. Ministerio de Cultura, Casa de Velázquez. Madrid: 121-140.

Berrocal-Rangel, L. (1994): “Oppida y castros de la Beturia céltica”. En M. Almagro-Gorbea y A. Ma . Martín (coords.), Castros y oppida en Extremadura. Complutum, No Extra-4: 189 - 241.

Berrocal-Rangel, L. (2004): "La defensa de la comunidad: sobre las funciones emblemáticas de las murallas protohistóricas en la Península Ibérica". Gladius, XXIV: 27-98, https://doi.org/10.3989/ gladius.2004.36.

Blánquez Pérez, J. (1993): "El poblado ibérico de La Quéjola”. Pátina, 6: 99-107.

Blánquez Pérez, J. (2013): “Arquitectura y poder: las fortalezas bárquidas en Hispania”. En M. Bendala Galán, M. Pérez Ruiz e I. Escobar (coords.), Fragor Hannibalis: Aníbal en Hispania. Comunidad de Madrid, Museo Arqueológico Regional. Madrid: 208-253.
Blánquez Pérez, J. y Roldán Gómez, L. (2009): “La muralla de casernas de la ciudad púnica de Carteia (San Roque, Cádiz)". Almoraima, 39: 93-104.

Blánquez Pérez, J.; Roldán Gómez, L. y Jiménez Vialás, H. (2017): "La nueva muralla púnica de Carteia (San Roque, Cádiz). Investigaciones del Proyecto Carteia Fase II (2006-2013)". En F. Prados Martínez y F. Sala Sellés (eds.), El Oriente de Occidente. Fenicios y púnicos en el área ibérica. VIII Edición del Coloquio Internacional del CEFyP en Alicante. Universidad de Alicante. Alicante: 509-536.

Bonet, H. y Mata Parreño, C. (2002): El Puntal dels Llops. Un fortín edetano. Servicio de Investigación Prehistórica, Serie de Trabajos Varios 99. Valencia.

Bonet, H. y Vives-Ferrándiz,J. (2009): "Sistemas de acceso y puertas de los poblados ibéricos del País Valenciano". Revista d'Arqueologia de Ponent, 19: 287-306.

Bonet, H. y Vives-Ferrándiz, J. (coords.) (2009). La Bastida de les Alcusses (Moixent, Valencia). Diputación de Valencia, Valencia.

Broncano Rodríguez, S. y Alfaro Arregui, Ma del M. (1997): Los accesos a la ciudad ibérica de Meca mediante sus caminos de ruedas. Serie de Trabajos Varios del S.I.P., 92. Diputación Provincial de Valencia, Valencia.

Brun, P. (2001): "Échelles d'intégration politique et contrôle des moyens de production en Europe". En L. Berrocal-Rangel y P. Gardes (coords.), Entre celtas e íberos. Las poblaciones protohistóricas de las Galias e Hispania. Real Academia de la Historia, Casa de Velázquez. Madrid: 29-43.

Ferrer Albelda, E. y Pliego Vázquez, R. (2010): “auxilium consanguineis karthaginiensis misere: un nuevo marco interpretativo de las relaciones entre Cartago y las comunidades púnicas de Iberia”. Mainake, XXXII(I): 525-557.

Ferrer Albelda, E. y Pliego Vázquez, R. (2013): "Cartago e Iberia antes de los Barca”. En M. Bendala Galán, M. Pérez Ruiz e I. Escobar (coords.), Fragor Hannibalis: Aníbal en Hispania. Comunidad de Madrid, Museo Arqueológico Regional. Madrid: 106-133.

García Cardiel, J. (2017): "La Contestania ibérica frente a Cartago: fenómenos regionales y respuestas locales". Gerión, 35(2): 401-425, https://doi.org/ 10.5209/GERI.59917.

García Huerta, R.; Morales Hervás, F. J. y Rodríguez González, D. (2015). "Sistemas defensivos y control del territorio en la Oretania Septentrional". En O. Rodríguez Monterrubio, R. Portilla Casado, J. Carlos Sastre y P. Fuentes Melgar (coords.), Fortificaciones en la Edad del Hierro: control de los recursosy el territorio. Glyphos Publicaciones, Zamora: 175-193. 
Gracia Alonso, F. (1994): "Las Copas de Cástulo en la Península Ibérica: problemática y ensayo de clasificación". Huelva Arqueológica, 13(1): 175-200.

Gracia Alonso, F. (2005): "Las cerámicas griegas en elárea occidental de la península ibérica entre los siglos VI y IV a.C. El conjunto de materiales del palaciosantuario de Cancho Roano (Zalamea de la Serena, Badajoz)". En S. Celestino Pérez y J. Jiménez Ávila (eds.), El Periodo Orientalizante. Actas del III Simposio Internacional de Arqueología de Mérida: Protohistoria del Mediterráneo Occidental, Volumen III. Anejos de AEspA, XXXV. CSIC, Mérida: 1173-1197.

Gracia Alonso, F. (2006): "Las fortificaciones ibéricas. Análisis poliorcético y concepto de empleo táctico en la guerra de sitio". En A. Oliver Foix (coord.), Arquitectura defensiva: la protección de la población y del territorio en época ibérica. Sociedad Castellonense de Cultura. Castellón: 63-122.

Gracia Alonso, F. y Munilla, G. (2004): Protohistoria. Pueblos y culturas en el Mediterráneo entre los siglos XIV y II a.C. Universitat de Barcelona. Barcelona.

Guérin, P. (2003). El Castellet de Bernabé y el horizonte ibérico pleno edetano. Serie de Trabajos Varios del S.I.P., 100. Diputación de Valencia, Valencia.

Gutiérrez Soler, L. Mª .; López Castro, J. L. y Martínez Hahnmüller, V. (2017): “Giribaile, una Plaza Fuerte cartaginesa en el contexto de la ocupación bárquida del Alto Guadalquivir". En F. Prados Martínez y F. Sala Sellés (eds.), El Oriente de Occidente. Fenicios y púnicos en el área ibérica. Universidad de Alicante. Alicante: 385-401.

Lorrio Alvarado, A. (2007): "El Molón (Camporrobles, Valencia) y su territorio: fortificaciones y paisaje fortificado de un espacio de frontera". En L. BerrocalRangel y P. Moret (coords.), Paisajes fortificados de la Edad del Hierro: las murallas protohistóricas de la meseta y de la vertiente atlántica en su contexto europeo. Actas del coloquio celebrado en la Casa de Velázquez, (octubre de 2006). Real Academia de la Historia, Casa de Velázquez. Madrid: 213-236.

Lorrio Alvarado, A. (2011): "El Castellar de Meca: anatomía de un oppidum ibérico". Jornadas de Estudios Locales-Almansa, 9: 95-141.

Manzaneda Martín, C. (2017): "La influencia feniciopúnica y su reflejo en el ámbito religioso de la Oretania". En F. Prados Martínez y F. Sala Sellés (eds.), El Oriente de Occidente. Fenicios y púnicos en el área ibérica. Universidad de Alicante. Alicante: 587-608.

Miguel Naranjo, P. (2014): "Nuevos testimonios de cerámica griega en el yacimiento de Calatrava la Vieja (Carrión de Calatrava, Ciudad Real)". Sautuola, XIX: 235-246.
Moneo, T. Pérez Avilés, J. J. y Vélez Rivas, J. (2001): “Un santuario de entrada ibérico en «El Cerro de las Cabezas» (Valdepeñas, Ciudad Real)". Complutum, 12: 123-136.

Montanero Vico, D. y Asensio i Vilaró, D. (2009): "Puertas fortificadas del Mediterráneo: orígenes y evolución”. Revista d'Arqueologia de Ponent, 19: 177-204.

Morena López, J. A. (2010): "Investigaciones recientes en Torreparedones (Baena, Córdoba): prospección geofísica y excavaciones en el santuario y puerta oriental". En VV.AA., El Mausoleo de los Pompeyos de Torreparedones (Baena, Córdoba): análisis historiográfico y arqueológico. Salsvm 1. Monografías del Muro Histórico Municipal de Baena. Diputación de Córdoba, Ayto. de Baena. Córdoba: 171-208.

Morena López, J. A.; Moreno Rosa, A. y Ariza Rodríguez, F. J. (2007): "Investigaciones en Torreparedones". Baena arqueológica. Boletín informativo del Museo Histórico Municipal de Baena (Córdoba), 2: 2-4.

Moret, P. (1996): Les fortifications ibériques. De la fin de l'âge du Bronze à la conquête romaine. Collection de la Casa de Velázquez, 56. Casa de Velázquez, Madrid.

Moret, P. (1998): “«Rostros de Piedra». Sobre la racionalidad del proyecto arquitectónico de las fortificaciones urbanas ibéricas". Saguntum, No Extra-1. Actas del Congreso Internacional "Los Iberos, Príncipes de Occidente". Valencia: 83-92.

Oliva Prat, M. (1960): Excavaciones arqueológicas en la ciudad ibérica de Ullastret (Gerona). Undécima campaña de trabajos. Ed. Instituto de Estudios Gerundenses. Gerona.

Oliver Foix, A. (1995): "La presencia púnica en los asentamientos ibéricos: una aproximación a su problemática". Actes du III Congrés International des Études Phéniciennes et Puniques. Túnez, 1991. Túnez: 282-296.

Olmos Benlloch, P. (2009-11): "Modulación y proporción en la arquitectura emporitana entre los siglos VI-II a.C.". Empúries, 56: 125-141.

Pallarés Comas, R. (1983-1984): "El sistema defensivo frontal del Castellet de Banyoles, Tivissa, Ribera d' Ebre". Pyrenae, 19-20: 113-126.

Prados Martínez, F. (2007a): "La edilicia púnica y su reflejo en la arquitectura ibérica: materiales, aparejos y técnicas constructivas". Pallas,75: 9-35.

Prados Martínez, F. (2007b): "La presencia neopúnica en la Alta Andalucía: a propósito de algunos referentes arquitectónicos y culturales de época bárquida (237205 a.C.)". Gerión, 25(1): 83-110.

Prados Martínez, F. y Jiménez Vialás, H. (2017): "Menorca entre fenicios y púnicos: una aproximación arqueológica desde la arquitectura defensiva". En F. Prados Martínez, H. Jiménez Vialás y J. Ma Martínez (coords.), Menorca entre feniciosy púnicos. Publi- 
cacions des Born, 25. Universidad de Murcia. Murcia: 105-136.

Quesada Sanz, F. (2002-2003): "Innovaciones de raíz helenística en el armamento y tácticas de los pueblos Ibéricos desde el siglo III a.C.”. CuPAUAM, 28-29: 69-94, https://doi.org/10.15366/cupauam 2003.29.005.

Quesada Sanz, F. (2007): “Asedio, sitio, asalto...aspectos prácticos de la poliorcética en la iberia prerromana". En L. Berrocal-Rangel y P. Moret (eds.), Paisajes fortificados de la Edad del Hierro. Las murallas protohistóricas de la meseta y la vertiente atlántica en su contexto europeo. Real Academia de la Historia, Casa de Velázquez. Madrid: 75-98.

Quesada Sanz, F.; Kavanagh, E. y Lanz Domínguez, M. (2014): "Los molinos del yacimiento del Cerro de la Cruz (Almedinilla, Córdoba): clasificación y análisis de los ejemplares de época ibérica y emiral". Spal, 23: 83-118, https://doi.org/10.12795/spal. 2014.i23.05.

Reguero González,J. (2018): Arqueología de la arquitectura. El oppidum oretano de «El Cerro de las Cabezas» (Valdepeñas, Ciudad Real). Sistemas de almacenamiento. Trabajo de Fin de Máster, Universidad Autónoma de Madrid.

Rodanés Vicente, J. Ma . y Picazo Millán, J. V. (20132014): "Influencias orientales en el sistema defensivo de los poblados de la Primera Edad del Hierro del Cabezo de la Cruz (La Muela, Zaragoza)". Saldvie, 13-14: 213-231.

Roldán Gómez, L.; Bendala Galán, M.; Blánquez Pérez, J.; Martínez Lillo, S. y Bernal Casasola, D. (2003): Carteia II. Junta de Andalucía, CEPSA. Madrid.

Roldán Gómez, L.; Bendala Galán, M.; Blánquez Pérez,J. y Martínez Lillo, S. (dirs) (2006): Estudio históricoarqueológico de la ciudad de Carteia (San Roque, Cádiz). 1994-1999. Junta de Andalucía, Universidad Autónoma de Madrid. Sevilla.

Sala Sellés, F. (2004): "La influencia del mundo fenicio y púnico en las sociedades autóctonas del Sureste peninsular". Colonialismo e interacción cultural: el impacto fenicio-púnico en las sociedades autóctonas de Occidente (XVIII Fornadas de Arqueología Fenicio-Púnica. Eivissa, 2003). Govern Illes Balears. Eivissa: 57-102

Sala Sellés, F. (2010): "Nuevas perspectivas sobre las relaciones púnicas con la costa ibérica del sureste peninsular". Mainake, XXXII: 933-950.

Sanmartí, E.; Castañer, P. y Tremoleda, J. (1988): "La secuencia histórico-topográfica de las murallas del sector meridional de Emporion". Madrider Mitteilungen, 29: 191-200.

Schattner, T. G. (2005): "La Puerta de Sevilla en Carmona y otras puertas romanas en la península Ibérica”. Romula, 4: 67-98.
Sconfienza, R. (2005): Fortificazioni tardo classiche e ellenistiche in Magna Grecia. I casi esemplari nell'Italia del Sud. BAR International Series 1341. Oxford.

Seco Serra, I. (2010): Piedras con alma. El betilismo en el mundo antiguo y sus manifestaciones en la Península Ibérica. SPAL Monografias XIII. Sevilla.

Torres González, T.; Vélez Rivas, J.; Fernández Maroto, D.; Pérez Avilés, J.J. y Menchén Herreros, G. (e.p.): "El sistema defensivo de El Cerro de las Cabezas (Valdepeñas, Ciudad Real). Estudio de las fortificaciones de la zona oretana". I Congreso Internacional Cátedra Complutense de Historia Militar. Perspectivas y novedades de la historia militar: una aproximación global (22-24 de octubre de 2013).

Tréziny, H. (2011): "Fossés et défenses avancées dans les villes grecques d'Occident". Revista d'Arqueologia de Ponent, 21: 287-296.

Uroz Sáez, J. (2012): “La colonia romana de Libisosa y sus precedentes". En G. Carrasco Serrano (coord.), La ciudad romana en Castilla-La Mancha. Ediciones Universidad Castilla-La Mancha, Cuenca: 87-130.

Vélez Rivas, J. y Pérez Avilés, J. J. (2008a): "La ciudad ibérica del Cerro de las Cabezas (Valdepeñas, Ciudad Real). Arquitectura monumental y áreas de culto". En J. Blánquez Pérez, S. González Reyero y L. Roldán Gómez (eds.), La cámara de Toya y la arquitectura monumental ibérica. Serie Varia 7. Universidad Autónoma de Madrid, Ayuntamiento Peal de Becerro, Madrid: 123-149.

Vélez Rivas, J. y Pérez Avilés, J.J. (2008b): “Un espacio de culto del siglo V en El Cerro de las Cabezas (Valdepeñas, Ciudad Real)". En J. Jiménez Ávila (ed.), Sidereum Ana I. El río Guadiana en época post-orientalizante. Anejos de AEspA, XLVI. CSIC, Mérida: 37-59.

Vélez Rivas, J. y Pérez Avilés, J. J. (2009): "El bastiónalmacén del Cerro de las Cabezas, Valdepeñas". En R. García Huerta y D. Rodríguez González (eds.), Sistemas de almacenamiento entre los pueblos prerromanos peninsulares. Universidad de Castilla-La Mancha, Cuenca: 241-256.

Vélez Rivas, J.; Pérez Avilés, J. J. y Carmona Astillero, M. (2004): "El Cerro de las Cabezas: una ciudad fortificada". En A. Caballero Klink y J. L. Ruíz Rodríguez (coords.), Investigaciones Arqueológicas en Castilla LaMancha: 1996-2002. Junta de Comunidades de Castilla-La Mancha. Toledo: 91-104.

Zarzalejos Prieto, Ma . del M.; Fernández Ochoa, C.; Hevia Gómez, P. y Esteban Borrajo, G. (1995): "Cerámicas griegas de Sisapo (La Bienvenida, Ciudad Real". En Actas del XXII Congreso Nacional de Arqueología: Vigo 1993, Vol. 1: 183-190. 